\title{
Aromas of Salvia Species Enhance Everyday Prospective Memory Performance in Healthy Young Adults
}

\author{
Mark Moss*, Michelle Rouse, Lucy Moss \\ Brain, Performance and Nutrition Research Centre, Department of Psychology, Northumbria University, \\ Newcastle upon Tyne, UK \\ Email: "
}

Received 17 June 2014; revised 27 June 2014; accepted 2 July 2014

Copyright @ 2014 by authors and Scientific Research Publishing Inc.

This work is licensed under the Creative Commons Attribution International License (CC BY). http://creativecommons.org/licenses/by/4.0/

(c) (i) Open Access

\begin{abstract}
Research has previously demonstrated that aromas of both Salvia officinalis and Salvia lavandulaefolia are capable of modulating aspects of retrospective memory, attention and mood. This study is the first to report the potential for these aromas to enhance everyday prospective memory performance in healthy young adults. In an independent groups design, three conditions, Salvia officinalis aroma, Saliva lavandulaefolia aroma and no aroma were employed with 45 healthy volunteers in each condition. Prospective memory performance was assessed using the Prospective Remembering Video Procedure. Data analysis revealed that the Salvia officinalis aroma group performed significantly better than the control group on both event and action subscales of the prospective memory task. Saliva lavandulaefolia aroma only led to enhancement for the event measure when compared to controls. No differences were found between the aroma conditions. These findings offer support for those previously reported for the effects of the aromas of Salvia sp. on cognition and again demonstrate differential effects of the two aromas. The results are considered in terms of pharmacological mechanisms.
\end{abstract}

\section{Keywords}

Salvia, Sage, Aroma, Everyday Memory

\section{Introduction}

History records the extensive use of herbal medicines and other plant derived products for the treatment of

${ }^{*}$ Corresponding author.

How to cite this paper: Moss, M., Rouse, M. and Moss, L. (2014) Aromas of Salvia Species Enhance Everyday Prospective Memory Performance in Healthy Young Adults. Advances in Chemical Engineering and Science, 4, 339-346.

http://dx.doi.org/10.4236/aces.2014.43037 
health problems, and the improvement of day to day living. However, the development of synthetic drugs, often from analogues of natural compounds, overshadowed the use of herbal therapeutics [1]. Recent times have witnessed a resurgence of such alternative therapies, with alternative herbal medicines being used along side or instead of the more conventional treatments [2], with one of the main focuses being the attempt to find treatments to combat age-associated cognitive decline [3].

Of interest in this respect has been the Salvia genus, in particular Salvia officinalis (SO) and Salvia lavandulaefolia (SL). Although relatively new with respect to systematic scientific research the findings reported to date regarding the efficacy of extracts of these species have been very promising. The demonstrations that extracts of Salvia sp. possess acetylcholinesterase inhibitor properties [4]-[6] suggest a potential for cognitive modulation, and some investigations of clinical effects have been made in relation to such properties. For example [7], administered an alcoholic extract of SO leaf in a double blind intervention for mild to moderate Alzheimer's disease over a four month period. The authors reported significantly improved cognitive ability and decreased agitation when compared to the placebo control group.

A body of research has also been directed at performance and mood effects in healthy young volunteers. Kennedy et al. [8], administered an extract of SO prior to completion of defined intensity stressor battery and reported significantly improved performance on the Stroop sub-task, and positively modulated mood in the higher dose SO group. Similarly, Tildesley [9] administered SO extracts to healthy young volunteers and reported significantly enhanced word recall for various doses of SO when compared to the placebo control group. Additionally, a study employing older participants found significant improvements following SO administration for the quality of memory and the quality of attention factors derived from the Cognitive Drug Research (CDR) cognitive assessment system [10]. This study however did not find any effects for self-reported changes in mood indicating that the potential for cognitive enhancement is not necessarily dependent on changes in subjective state.

Studies of Salvia lavandulaefolia have also provided converging evidence regarding the efficacy of the Salvia genus. Tildesley, et al. [11] orally administered SL essential oil and the findings suggested dose dependant memory enhancements, with the major improvements in word recall being for $50 \mu \mathrm{l}$ dosage group. In a second study, participants were given either a placebo or $25 \mu$ or $50 \mu$ of SL essential oil. The CDR system was again used to assess cognitive function at 1, 2.5, 4 and 6 hours following administration. Significant improvements were found for both doses of the SO essential oil when compared to the placebo group. Specifically improvements were reported for the secondary memory and speed of memory factors-although at differing time points and doses [12].

There is currently a new momentum in the research of essential oils, with an increasing focus on the aromas of the essential oils and their putative effects on cognitive ability and mood. Employing the CDR assessment system, Moss et al. [13], reported that the aromas of Lavender and Rosemary essential oils produced differential effects for the quality of memory factor, and significant enhancements were seen for Rosemary on the secondary memory factor compared to both Lavender and no aroma control groups. Mood assessments were also significantly affected, with rosemary producing increased alertness and contentedness. Further to this, Moss and colleagues found that peppermint aroma resulted in significantly improved quality of memory when compared to ylang-ylang aroma and a no aroma control group [14]. These findings were found not to be associated with changes in mood measurements. It has been suggested that the aromas of essential oils may have similar effects as oral ingestion of plant extracts as a consequence of the absorption of volatile active components via the lungs. This follows the work of Kovar et al. [15] who found significant increases when monitoring locomotor activity in rats after oral administration of rosemary; A finding that was mirrored after the inhalation of rosemary aroma. This evidence might suggest that when the aromas of Salvia sp. are inhaled, enhancements in cognitive abilities of a similar magnitude and manner to those observed when herbal extracts are taken orally could be seen. Indeed, Moss et al., report a study that investigated the effects of Salvia sp. aromas, and make a qualitative comparison to those previously reported for oral administration of the herbs concluding that a general, but not universal, picture of similar effects was present [16]. Furthermore, in a recent study significant correlations were found between plasma borne 1,8-cineole and cognitive performance following exposure to rosemary aroma [17], strongly supporting the contention that aromas may act pharmacologically.

Prospective memory (PM) is an important aspect of everyday functioning, being the ability to remember to do something at some point in the future [18]. A failure of prospective memory can have a range of consequences, such as forgetting an appointment or to take prescribed drugs at appropriate times. An increasing amount of re- 
search has been focussed on the decline in PM in old age and dementia with evidence of decline, exaggerated in dementia patients, coming from both questionnaire [19] and naturalistic methods [20]. In respect of the younger population, the majority of research has focussed on how lifestyle choices e.g. alcohol and recreational drug use might impact upon PM, with a general consensus that substance use impairs both subjective ratings [21] [22] and objective performance [23] even when subjective self-assessment records no decrements [24] [25]. However, little or no research has addressed the potential to improve performance on PM tasks, with that which has focussing on behavioural [26] and psychosocial interventions [27]. Given the lack of research in the area, the current study aims to assess the effects of Salvia officinalis and Salvia lavandulaefolia essential oil aromas on an objective video based measure of prospective memory performance.

\section{Materials and Methods}

\subsection{Design}

A single-blind, one factor, independent groups design was employed in this study. The independent variable was aroma condition and had three levels: Salvia officinalis aroma, Salvia lavandulaefolia aroma and no aroma (control). The dependent variables were Total, Event and Action scores from the video based prospective memory task. The overall sample size was calculated using $G *$ Power and based on a power of 0.8 and an effect size of $f=0.25$ calculated from previous aroma studies [13] [14] [16].

\subsection{Participants}

One hundred and thirty five healthy adult volunteers took part in the study. Recruitment took place through the automated participation pool provided by Sona-Systems Ltd. All volunteers were students in the School of Psychology and Sport Sciences at Northumbria University. All participants reported that they were non-smokers, had no history of respiratory disorders or decrements in their sense of smell. Participants were randomly allocated to the three conditions. The Salvia officinalis aroma condition was made up of 37 females (mean age = 21.3, $\mathrm{SD}=3.6$ ) and 8 males (mean age $=22.4, \mathrm{SD}=3.0$ ). The Salvia lavandulaefolia aroma condition was made up of 36 females (mean age $=21.3$, SD $=4.9$ ) and 9 males (mean age $=23.1, \mathrm{SD}=3.8$ ), and the control (no aroma) condition was made up of 36 females (mean age $=21.3, \mathrm{SD}=4.4$ ) and 9 males (mean age $=23.9$, $\mathrm{SD}=$ 4.4). Ethical approval for the study was obtained from the Department of Psychology Ethics Committee at Northumbria University.

\subsection{Testing Cubicles}

Testing cubicles measured $2.4 \mathrm{~m}$ long $\times 1.8 \mathrm{~m}$ wide $\times 2.4 \mathrm{~m}$ high and were maintained at a temperature of between 18 and 22 degrees Celsius throughout the testing sessions. The doors were kept closed except for participant access. Three identical cubicles were used and testing took place on three different days of the week (Monday, Wednesday, and Friday) to avoid cross contamination of aromas.

\subsection{Aromas}

The essential oils of Salvia officinalis and Salvia lavandulaefolia were used to provide the aromas. Both species were organically grown in Europe and were obtained from NHR organic essential oils, Brighton, UK. To diffuse the aroma, an "aroma stone" (Naturally thinking, Carshalton, Surrey, UK) was used. Five drops of the appropriate essential oil and $5 \mathrm{ml}$ water were placed on the stone and left to diffuse into the testing cubicle, as a result of the constant temperature warming provided by the stone, for five minutes prior to testing each participant.

\subsection{Prospective Memory Measures}

Objective Prospective Memory (PM) was measured by the PRVP based on a methodology used by earlier researchers to study cannabis [28] and binge-drinking [24]. The PRVP involved presenting a list of 21 specific locations (e.g. "when you reach the store W. H. Smiths"), which were accompanied by a list of associated actions (e.g. "ask if there is a job available") which the respondent viewed for 1.5 minutes. This was immediately followed by a ten-minute video clip of a busy shopping area depicting a range of shop fronts and passers-by that provided location cues during which the previously presented location-action combinations were recalled (see 
Table 1 for the full list of combinations). Before watching the video clip, the participant was instructed to remember each of the location-action pairings for later recall when viewing the video clip. The researcher ensured that the participant was aware that he/she should only write down each location-action combination on a blank response sheet when the familiar location was reached on viewing the video and not before. These instructions were given to ensure that the participant did not merely write down a list of location-action combinations at the start of the video clip, rather they recalled each combination as part of the ongoing PM task whilst monitoring the video clip. In addition to the main target locations, several other locations/occurrences were included which were not contained in the to-be-remembered list, acting as non-target distracter locations (e.g. passing other shop fronts, passers-by who talked to the camera). The inclusion of such was to ensure that the PM task was as similar to a more realistic PM scenario as possible [29]. One point was given for each location-action combination correctly recalled, ranging from $0-21$ points per respondent, with the higher the score on the PRVP indicating the better one's PM is concluded to be. The PRVP has been used in previous research [24] [28] and shows good reliability $(\alpha=0.68)$.

\subsection{Sensory Variables}

Likert scales were used to assess participants' ratings of pleasantness and strength of ambient aromas. The scales ranged from 1 to 5 with higher values indicating stronger ratings of the variables.

\subsection{Procedure}

All testing took place on an individual basis between 9:00 and 12:00. Participants were informed that they were taking part in the validation of a testing system and no information was provided regarding the aromas prior to testing. Following the completion of a number of computerised tasks the video based prospective memory assessment began. To conclude the experiment the participants were fully debriefed and thanked for their time.

\subsection{Results}

Descriptive statistics for the dependent variables appear in Table 2. The data were analysed by way of one way independent groups ANOVAs using the statistical package SPSS 16 for windows. Significant results were followed up with Tukey post-hoc pairwise comparisons.

Table 1. A full list of the 18 event-action/memory combinations used on the PRVP.

\begin{tabular}{|c|c|}
\hline Event & Action \\
\hline When you reach the Halifax & Check if your loan has cleared \\
\hline When you see 1st man pushing pushchair & Use mobile to text \\
\hline When you see a woman sitting on a bench & Ask her the time \\
\hline When you reach the store Dixons & Note how much "Play Station 2” costs \\
\hline When you see girl sitting with dog & Note the colour of jacket of woman petting dog \\
\hline At H Samuels & Buy a watch battery \\
\hline At W H Smiths & Ask if any job available \\
\hline At HMV & Buy an album \\
\hline At Burger King & Buy a Milkshake \\
\hline When you pass Flower Stall & Note the colour of stall's roof \\
\hline At Wallis & Note how many Phone Boxes there are \\
\hline At Thornton's & Buy bag of toffees \\
\hline At the "Orange" shop & Buy a $£ 10$ top-up card \\
\hline At Boots Store & Note what the boy is wearing on his face \\
\hline At the mobile phone stall & Ask directions to station \\
\hline At the Link & Note what instrument man is playing \\
\hline When you meet a man asking for change & Check your pocket for $20 \mathrm{p}$ \\
\hline At the picture Stall & Note who the famous bear is \\
\hline
\end{tabular}


Table 2. Means (standard deviations) for the prospective memory video task.

\begin{tabular}{cccc}
\hline & Total & Event & Action \\
\hline S. officinalis & $15.8(5.3)$ & $9.4(2.4)$ & $6.4(3.2)$ \\
S. lavandulaefolia & $14.5(5.2)$ & $8.8(2.1)$ & $5.7(3.3)$ \\
Control & $11.8(2.9)$ & $7.2(1.4)$ & $4.6(2.1)$ \\
\hline
\end{tabular}

\subsubsection{Prospective Remembering Video Procedure Total Score}

The ANOVA identified significant differences between groups for the Total score on the PRVP $F(2,132)=$ 8.433, $\mathrm{p}<0.001, \eta_{\text {partial }}^{2}=0.113$. Tukey post hoc comparisons revealed both Salvia officinalis aroma (mean $=$ 15.8 ) and Salvia lavandulaefolia aroma (mean $=14.5$ ) conditions produced higher scores than the no aroma condition $($ mean $=11.9) ; \mathrm{p}<0.001$ and $=0.020$ respectively. The two aroma conditions did not differ significantly p $=0.393$.

\subsubsection{Prospective Remembering Video Procedure Event Score}

The ANOVA identified significant differences between groups for the Event score on the PRVP $F(2,132)=$ $13.441, \mathrm{p}<0.001, \eta_{\text {partial }}^{2}=0.169$. Tukey post hoc comparisons revealed both Salvia officinalis aroma (mean = 9.4) and Salvia lavandulaefolia aroma (mean $=8.8$ ) conditions produced higher scores than the no aroma condition (mean $=7.2$ ); $\mathrm{p}<0.001$ and $=0.001$ respectively. The two aroma conditions did not differ significantly $\mathrm{p}=$ 0.397.

\subsubsection{Prospective Remembering Video Procedure Action Score}

The ANOVA identified significant differences between groups for the Action score on the PRVP $\mathrm{F}(2,132)=$ 4.144, $\mathrm{p}=0.018, \quad \eta_{\text {partial }}^{2}=0.059$. Tukey post hoc comparisons revealed that Salvia officinalis aroma (mean $=$ 6.4) produced higher scores than the no aroma condition (mean $=4.6$ ); $\mathrm{p}=0.014$. The Salvia lavandulaefolia aroma (mean $=5.7$ ) conditions did not differ significantly to the $\mathrm{SO}$ or control condition, $\mathrm{p}=0.484$ and $\mathrm{p}=$ 0.206 respectively.

\subsubsection{Pleasantness of the Aroma}

The ANOVA identified significant differences between groups for the perceived pleasantness of the ambient aromas in the cubicles $\mathrm{F}(2,132)=4.683, \mathrm{p}=0.011, \quad \eta_{\text {partial }}^{2}=0.066$. Tukey post hoc comparisons revealed both Salvia officinalis aroma (mean $=3.8)$ and Salvia lavandulaefolia aroma (mean $=3.6$ ) conditions were rated as more pleasant than the no aroma condition (mean $=3.0$ ); $\mathrm{p}=0.039$ and 0.016 respectively. The two aroma conditions did not differ significantly $\mathrm{p}=0.942$.

\subsubsection{Strength of the Aroma}

The ANOVA identified significant differences between groups for the perceived intensity of the ambient aromas in the cubicles $\mathrm{F}(2,132)=20.207, \mathrm{p}<0.001, \eta_{\text {partial }}^{2}=0.185$. Tukey post hoc comparisons revealed both Salvia officinalis aroma (mean $=3.7$ ) and Salvia lavandulaefolia aroma (mean $=3.2$ ) conditions were rated as more intense than the no aroma condition (mean $=2.0$ ); $\mathrm{p}<0.001$ in both cases. The two aroma conditions did not differ significantly $\mathrm{p}=0.177$.

\section{Discussion}

Both Salvia officinalis and Salvia lavandulaefolia aromas produced a significant enhancement effect for the total scores on the video based prospective memory task. A more fine grained analysis of the scores revealed that this enhancement was restricted to "Event" based aspects of PM for Salvia lavandulaefolia aroma with no impact on action performance. In contrast, Salvia officinalis aroma significantly enhanced performance for both "Event" and "Action" based aspects of the task. The relationship between prospective memory and other forms of memory is something that engenders considerable debate [30], although there is some consensus that it may be seen as a separate and dissociable memory function [31]. As such, these findings provide interesting comparisons for effects on aspects of memory reported previously for both oral and aroma based administration of these herbs in 
healthy young participants. With regard to SO, Tildesley found a significant improvement in the quality of memory factor and more specifically the secondary memory sub-factor, but not the working memory sub-factor, following a $666 \mathrm{mg}$ dose of herbal extract when compared to the placebo control condition [9]. It has been argued that prospective memory only draws on working memory once the future event triggers an action. If the relationship were so, it might be predicted that SO aroma would not impact on the action measure of the task employed here. Given that this variable was enhanced by SO a more complex relationship might exist or indeed the systems serving PM performance might be distinct from working memory entirely. Interestingly however, in a study with a cohort of healthy elderly participants Scholey and colleagues reported much more striking effects following herbal SO administration [10]. As well as a positive effect on both secondary and working memory, the elderly also displayed an enhancement on the accuracy of attention factor. This may indicate that although perhaps not directly available for enhancement, working memory is open for the reversal of small decrements resultant of natural ageing. A study of the effects of aroma on prospective memory in the elderly may help elucidate the complex relationships between the different aspects of memory.

The significant difference found here between the SL aroma condition and the control condition for the "Event" scores might have been predicted based on previous research. Tildesley et al., reported significant improvements in the quality of memory factor scores following oral administration of both SL herb and essential oil [11] [12]. Acetylcholinesterase inhibition has been proposed as one of the major reasons why an improvement in cognition is observed when SL essential oil is orally administered [11]. Savelev et al. performed an in vitro study which showed that eight terpenoid constituents of SL essential oil displayed acetylcholinesterase inhibitory properties [4]. Rusted, Ruest \& Gray propose a mechanism by which compounds with cholinergic properties such as those found in extracts of Salvia sp. might enhance prospective memory [32]. Employing an event related fMRI procedure Rusted and colleagues demonstrated enhancements in prospective memory performance whilst concurrently completing an attention based task following nicotine administration. Such enhancements they argue are as a result of the cholinergic agonist properties of nicotine attenuating the attention drain that results from engaging with prospective memory tasks.

The effects reported here do not lend themselves to be easily explained by the hedonic valence mechanism. This mechanism suggests that the pleasantness of an aroma can impact on behaviour and emotional states [33], and some authors have reported that hedonic valence might also explain cognitive effects observed [34]. The two aromas employed here have distinctly different properties and effects, but were not rated differently in terms of pleasantness or strength. Similarly the differential effects found for aspects of prospective memory reported here do not lend themselves to explanation by the expectancy mechanism proposed by Howard and Hughes [35]. Although expectancy can be an important factor [36], it is unlikely that without expectancy manipulation the randomly allocated participants would have self-generated expectancies that produced the pattern outcomes observed.

Although the PRVP represents a useful method by which activities akin to everyday life can be tested in the laboratory, it does have its limitations that need to be considered by future researchers. A limitation of the current use of the PRVP is that it provided only a snapshot of everyday memory. As noted elsewhere [37] intentions are often carried out over prolonged delays (such as hours, or days, or weeks), whereas the present task was short in duration. Future research may wish to vary task duration, for example, comparing PRVP procedures that run for minutes with those running an hour (or more).

In order to further our understanding of herbs and herb-derived products such as essential oils, a number of practical approaches should be combined. The utilization of a single harvest source of herb to produce herbal and extract products for testing should be applied to allow accurate comparisons to be made in an area where standardised products do not exist. In addition in vitro analysis of pharmacological properties should be made to establish the levels of constituent compounds and their impact on neurotransmitter systems. Serum samples obtained from participants should be examined to assess if the active compounds have been absorbed, and to what extent following both oral ingestion and aroma exposure. If any active compounds are present in herb, essential oil and serum samples, and similar effects are observed for cognition and mood this would provide the strongest evidence yet that the mechanisms behind such effects are pharmacological.

\section{Declaration of Interest}

The authors report no conflicts of interest. The authors alone are responsible for the content and writing of the paper. 


\section{Conflicts}

There are no conflicts of interest (real or apparent) that may have a direct bearing on the subject matter of this article.

\section{References}

[1] Ryman, D. (1991) Aromatherapy: The Encyclopaedia of Plants and Oils and How They Help You. Judy Piatkus, London.

[2] Emslie, M.J., Campbell, M.K. and Walker, K.A. (2002) Change in Public Awareness of, Attitudes to, and Use of Complementary Therapy in North East Scotland: Survey in 1993 and 1999. Complementary Therapies in Medicine, 10, 148-153. http://dx.doi.org/10.1016/S0965229902000663

[3] Mantle, D., Pickering, A.T. and Perry, E.K. (2000) Medical Plant Extracts for the Treatments of Dementia: A Review of Their Pharmacology, Efficacy and Tolerability. CNS Drugs, 13, 201-213. http://dx.doi.org/10.2165/00023210-200013030-00006

[4] Savelev, S., Okello, E., Perry, N.S.L., Wilkins, R.M. and Perry, E.K. (2003) Synergistic and Antoagonistic Interactions of Anticholinesterase Terpenoids in Salvia lavandulaefolia Essential Oil. Pharmacology, Biochemistry and Behaviour, 75, 661-668. http://dx.doi.org/10.1016/S0091-3057(03)00125-4

[5] Perry, N., Court, G., Bidet, N., Court, J. and Perry, E. (1996) European Herbs with Cholinergic Activities: Potential in Dementia Therapy. International Journal of Geriatric Psychiatry, 11, 1063-1069. http://dx.doi.org/10.1002/(SICI)1099-1166(199612)11:12<1063::AID-GPS532>3.0.CO;2-1

[6] Perry, N.S.L., Houghton, P., Theobald, A., Jenner, P. and Perry, E.K. (2000) In Vitro Inhibition of Human Erythrocyte Acetylcholinesterase by Salvia lavandulaefolia Essential Oil and Constituents Terpenes. Journal of Pharmacology, 52, 895-902. http://dx.doi.org/10.1211/0022357001774598

[7] Akhondzadeh, S., Noroozian, M., Mohammadi, M., Ohadinia, S., Jamshidi, A.H. and Khani, M. (2003) Salvia officinalis Extract in the Treatment of Patients with Mild to Moderate Alzheimer's Disease: A Double Blind, Randomized and Placebo-Controlled Trial. Journal of Clinical Pharmacy and Therapeutics, 28, 53-59. http://dx.doi.org/10.1046/j.1365-2710.2003.00463.x

[8] Kennedy, D.O., Pace, S., Haskell, C., Okello, E.J., Milne, A. and Scholey, A.B. (2006) Effects of Cholinesterase Inhibiting Sage (Salvia officinalis) on Mood, Anxiety and Performance on a Psychological Stressor Battery. Neuropsychopharmacology, 31, 845-852. http://dx.doi.org/10.1038/sj.npp.1300907

[9] Tildesley, N.T.J. (2007) The Neurocogntive Effects of Salvia (Sage) in Health and Disease. Ph.D. Thesis, Northumbria University, Newcastle upon Tyne, Unpublished.

[10] Scholey, A.B., Tildesley, N.T.J., Ballard, C.G., Wesnes, K.A., Tasker, A., Perry, E.K. and Kennedy, D.O. (2008) An Extract of Salvia (Sage) with Anticholinesterase Properties Improves Memory and Attention in Healthy Older Volunteers. Psychopharmacology, 198, 127-139. http://dx.doi.org/10.1007/s00213-008-1101-3

[11] Tildesley, N.T.J., Kennedy, D.O., Perry, E.K., Ballard, C.G., Savelev, S., Wesnes, K.A. and Scholey, A.B. (2003) Salvia lavandulaefolia (Spanish Sage) Enhances Memory in Health Young Volunteers. Pharmacology, Biochemistry and Behaviour, 75, 669-674. http://dx.doi.org/10.1016/S0091-3057(03)00122-9

[12] Tildesley, N.T.J., Kennedy, E.K., Perry, C.G., Ballard, C.G., Wesnes, K.A. and Scholey, A.B. (2005) Positive Modulation of Mood and Cognitive Performance Following Administration of Acute Doses of Salvia lavandulaefolia Essential Oil to Healthy Young Volunteers. Physiology and Behaviour, 83, 699-709. http://dx.doi.org/10.1016/j.physbeh.2004.09.010

[13] Moss, M., Cook, J., Wesnes, K. and Duckett, P. (2003) Aromas of Rosemary and Lavender Essential Oils Differently Affect Cognition and Mood in Healthy Adults. International Journal of Neuroscience, 113, 15-38. http://dx.doi.org/10.1080/00207450390161903

[14] Moss, M., Hewitt, S., Moss, L. and Wesnes, K. (2008) Modulation of Cognitive Performance and Mood by Aromas of Peppermint and Ylang-Ylang. International Journal of Neuroscience, 118, 59-77. http://dx.doi.org/10.1080/00207450601042094

[15] Kovar, K.A., Gropper, B., Friess, D. and Ammon, H.R.T. (1987) Blood Levels of 1,8-Cineole and Locomotor Activity of Mice after Inhalation and Oral Administration of Rosemary Oil. Planta Medica, 53, 315-318. http://dx.doi.org/10.1055/s-2006-962725

[16] Moss, L., Rouse, M. and Moss, M. (2010) Differential Effects of the Aromas of Salvia Species on Memory and Mood. Human Psychopharmacology-Clinical and Experimental, 25, 388-396.

[17] Moss, M. and Oliver, L. (2012) Plasma 1,8-Cineole Correlates with Cognitive Performance Following Exposure to Rosemary Essential Oil Aroma. Therapeutic Advances in Psychopharmacology, 2, 103-113. 
http://dx.doi.org/10.1177/2045125312436573

[18] Brandimonte, M., Einstein, G.O. and McDaniel, M.A. (1996) Prospective Memory: Theory and Applications. Lawrence Erlbaum Associates, New York.

[19] Smith, G., Della Sala, S., Logie, R.H. and Maylor, E.A. (2000) Prospective and Retrospective Memory in Normal Ageing and Dementia: A Questionnaire Study. Memory, 8, 311-321. http://dx.doi.org/10.1080/09658210050117735

[20] Thompson, C.L., Henry, J.D., Withall, A., Rendell, P.G. and Brodaty, H. (2011) A Naturalistic Study of Prospective Memory in MCI and Dementia. British Journal of Clinical Psychology, 50, 425-434. http://dx.doi.org/10.1111/j.2044-8260.2010.02004.x

[21] Heffernan, T., O’Neill, T., Ling, J., Bartholomew, J. and Betney, G. (2006) Does Excessive Alcohol Use in Teenagers Affect Their Everyday Prospective Memory? Clinical Effectiveness in Nursing, 953, 302-307. http://dx.doi.org/10.1016/j.cein.2006.05.003

[22] Rogers, J., Buchanan, T., Scholey, A.B., Heffernan, T.M., Ling, J. and Parrott, A. (2003) Patterns of Drug Use and the Influence of Gender on Self-Reports of Memory Ability in Ecstasy Users: A Web-Based Study. Journal of Psychopharmacology, 17, 389-396. http://dx.doi.org/10.1177/0269881103174016

[23] Rendell, P.G., Gray, T.J., Henry, J.D. and Tolan, A. (2007) Prospective Memory Impairment in “Ecstasy” (MDMA) Users. Psychopharmacology, 194, 497-504. http://dx.doi.org/10.1007/s00213-007-0859-z

[24] Heffernan, T., Clark, R., Bartholomew, J., Ling, J. and Stephens, S. (2010) Does Binge Drinking in Teenagers Affect Their Everyday Prospective Memory? Drug and Alcohol Dependence, 109, 73-78. http://dx.doi.org/10.1016/j.drugalcdep.2009.12.013

[25] Heffernan, T., O’Neill, T. and Moss, M. (2010) Smoking and Everyday Prospective Memory: A Comparison of SelfReport and Objective Methodologies. Drug and Alcohol Dependence, 112, 234-238. http://dx.doi.org/10.1016/j.drugalcdep.2010.06.012

[26] McKitrick, L.A., Camp, C.J. and Black, F.W. (1992) Prospective Memory Intervention in Alzheimer's Disease. Journal of Gerontology, 47, 337-343. http://dx.doi.org/10.1093/geronj/47.5.P337

[27] Nater, U.M., Okere, U., Stallkamp, R., Moor, C., Ehlert, U. and Kliegel, M. (2006) Psychosocial Stress Enhances TimeBased Prospective Memory in Healthy Young Men. Neurobiology of Learning and Memory, 86, 344-348. http://dx.doi.org/10.1016/j.nlm.2006.04.006

[28] Bartholomew, J., Holroyd, S. and Heffernan, T.M. (2010) Does Cannabis Use Affect Prospective Memory in Young Adults? Journal of Psychopharmacology, 24, 241-246. http://dx.doi.org/10.1177/0269881109106909

[29] Ellis, J. and Kvavilashvili, L. (2000) Prospective Memory in 2000: Past, Present, and Future Directions. Applied Cognitive Psychology, 14, S1-S9. http://dx.doi.org/10.1002/acp.767

[30] Kliegel, M., McDaniel M.A. and Einstein, G.O. (Eds.) (2008) Prospective Memory: Cognitive, Neuroscience, Developmental, and Applied Perspectives. Lawrence Erlbaum Associates, New York.

[31] Salthouse, T.A., Berish, D.E. and Siedlecki, K.L. (2004) Construct Validity and Age Sensitivity of Prospective Memory. Memory \& Cognition, 32, 1133-1148. http://dx.doi.org/10.3758/BF03196887

[32] Rusted, J., Ruest, T. and Gray, M.A. (2011) Acute Effects of Nicotine Administration during Prospective Memory, an Event Related fMRI Study. Neuropsychologica, 49, 2362-2368. http://dx.doi.org/10.1016/j.neuropsychologia.2011.04.009

[33] Baron, R.A. and Bronfen, M.I. (1994) A Whiff of Reality: Empirical Evidence Concerning the Effects of Pleasant Fragrances on Work-Related Behaviour. The Journal of Applied Social Psychology, 24, 1179-1203. http://dx.doi.org/10.1111/j.1559-1816.1994.tb01550.x

[34] Baron, R.A. and Thomley, J. (1994) A Whiff of Reality: Positive Affect as a Potential Mediator of Effects of Pleasant Fragrances on Task Performance and Helping. Environment and Behavior, 26, 766-784. http://dx.doi.org/10.1177/0013916594266003

[35] Howard, S. and Hughes, B.M. (2008) Expectancies, Not Aroma, Explain Impact of Lavender Aromatherapy on Psychophysiological Indices of Relaxation in Young Healthy Women. British Journal of Health Psychology, 13, 603-617. http://dx.doi.org/10.1348/135910707X238734

[36] Moss, M., Howarth, R., Wilkinson, L. and Wesnes, K. (2006) Expectancy and the Aroma of Chamomile Influence Mood and Cognition in Healthy Volunteers. International Journal of Aromatherapy, 16, 63-73. http://dx.doi.org/10.1016/j.ijat.2006.04.002

[37] Farrimond, S., Knight, R.G. and Titov, N. (2006) The Effects of Aging on Remembering Intentions: Performance on a Simulated Shopping Task. Applied Cognitive Psychology, 20, 533-555. http://dx.doi.org/10.1002/acp.1202 
Scientific Research Publishing (SCIRP) is one of the largest Open Access journal publishers. It is currently publishing more than 200 open access, online, peer-reviewed journals covering a wide range of academic disciplines. SCIRP serves the worldwide academic communities and contributes to the progress and application of science with its publication.

Other selected journals from SCIRP are listed as below. Submit your manuscript to us via either submit@scirp.org or Online Submission Portal.
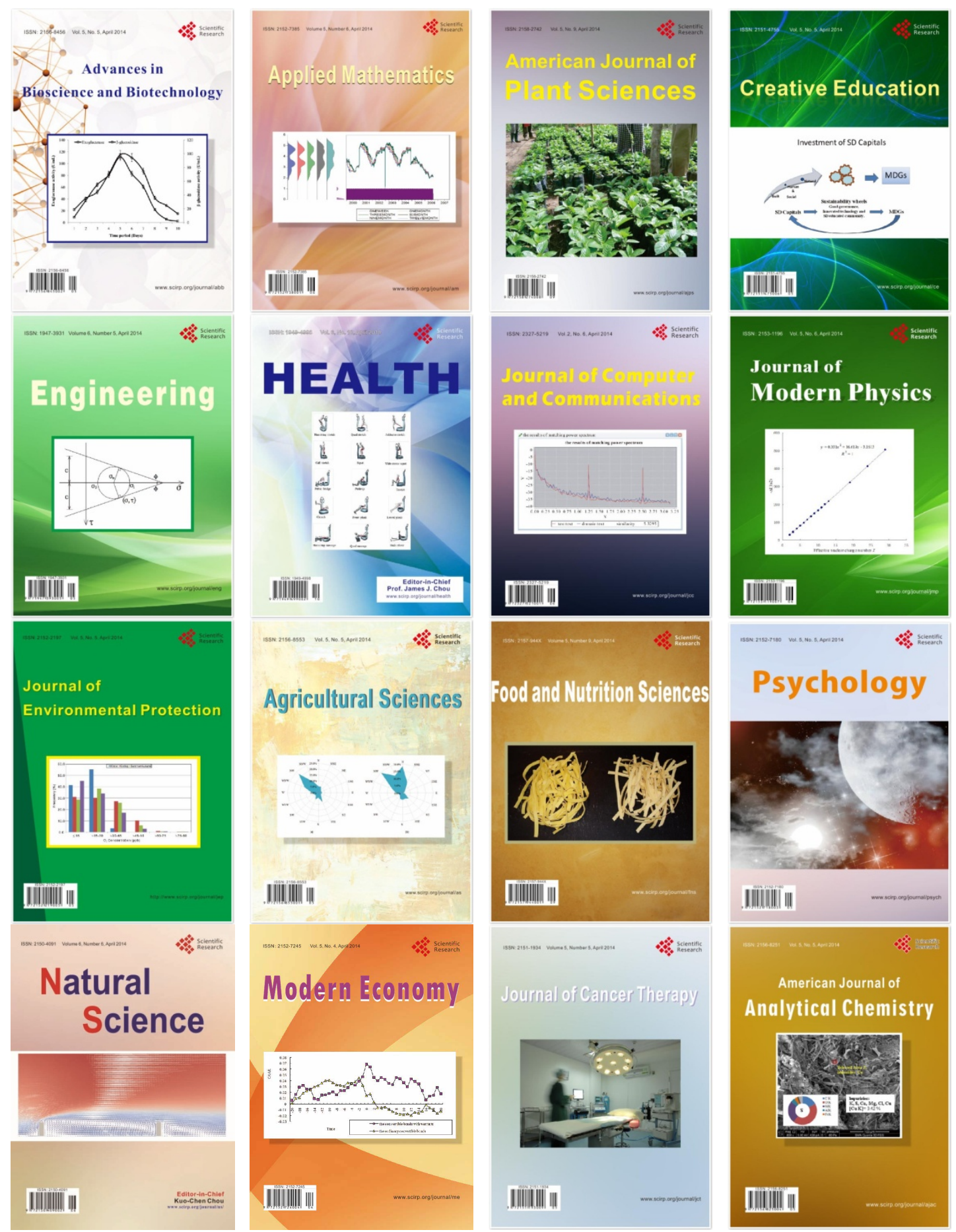